\title{
Planting Seeds So Something Bigger Might Emerge: The Paris Agreement and the Fight Against Climate Change
}

DOI:

10.1080/08854300.2016.1183992

\section{Document Version}

Accepted author manuscript

Link to publication record in Manchester Research Explorer

\section{Citation for published version (APA):}

Anderson, K., \& Nevins , J. (2016). Planting Seeds So Something Bigger Might Emerge: The Paris Agreement and the Fight Against Climate Change. Socialism and Democracy, 30(2), 209-218.

https://doi.org/10.1080/08854300.2016.1183992

\section{Published in:}

Socialism and Democracy

\section{Citing this paper}

Please note that where the full-text provided on Manchester Research Explorer is the Author Accepted Manuscript or Proof version this may differ from the final Published version. If citing, it is advised that you check and use the publisher's definitive version.

\section{General rights}

Copyright and moral rights for the publications made accessible in the Research Explorer are retained by the authors and/or other copyright owners and it is a condition of accessing publications that users recognise and abide by the legal requirements associated with these rights.

\section{Takedown policy}

If you believe that this document breaches copyright please refer to the University of Manchester's Takedown Procedures [http://man.ac.uk/04Y6Bo] or contact uml.scholarlycommunications@manchester.ac.uk providing relevant details, so we can investigate your claim.

\section{OPEN ACCESS}




\section{PROOF COVER SHEET}

Author(s): $\quad$ Kevin Anderson

Article Title: $\quad$ Planting Seeds So Something Bigger Might Emerge: The Paris Agreement and the Fight Against Climate Change

Article No: $\quad$ CSAD1183992

Enclosures: $\quad$ 1) Query sheet

2) Article proofs

Dear Author,

1. Please check these proofs carefully. It is the responsibility of the corresponding author to check these and approve or amend them. A second proof is not normally provided. Taylor \& Francis cannot be held responsible for uncorrected errors, even if introduced during the production process. Once your corrections have been added to the article, it will be considered ready for publication.

Please limit changes at this stage to the correction of errors. You should not make trivial changes, improve prose style, add new material, or delete existing material at this stage. You may be charged if your corrections are excessive (we would not expect corrections to exceed 30 changes).

For detailed guidance on how to check your proofs, please paste this address into a new browser window: http://journalauthors.tandf.co.uk/production/checkingproofs.asp

Your PDF proof file has been enabled so that you can comment on the proof directly using Adobe Acrobat. If you wish to do this, please save the file to your hard disk first. For further information on marking corrections using Acrobat, please paste this address into a new browser window: http:// journalauthors.tandf.co.uk/production/acrobat.asp

2. Please review the table of contributors below and confirm that the first and last names are structured correctly and that the authors are listed in the correct order of contribution. This check is to ensure that your name will appear correctly online and when the article is indexed.

\begin{tabular}{|l|l|l|l|l|}
\hline Sequence & Prefix & Given name(s) & Surname & Suffix \\
\hline 1 & & Kevin & Anderson & \\
\hline 2 & & Joseph & Nevins & \\
\hline
\end{tabular}


Queries are marked in the margins of the proofs, and you can also click the hyperlinks below.

Content changes made during copy-editing are shown as tracked changes. Inserted text is in red font and revisions have a red indicator $\_$. Changes can also be viewed using the list comments function. To correct the proofs, you should insert or delete text following the instructions below, but do not add comments to the existing tracked changes.

\section{AUTHOR QUERIES}

\section{General points:}

1. Permissions: You have warranted that you have secured the necessary written permission from the appropriate copyright owner for the reproduction of any text, illustration, or other material in your article. Please see http://journalauthors.tandf.co.uk/permissions/usingThirdPartyMaterial.asp.

2. Third-party content: If there is third-party content in your article, please check that the rightsholder details for re-use are shown correctly.

3. Affiliation: The corresponding author is responsible for ensuring that address and email details are correct for all the co-authors. Affiliations given in the article should be the affiliation at the time the research was conducted. Please see http://journalauthors.tandf.co.uk/preparation/ writing.asp.

4. Funding: Was your research for this article funded by a funding agency? If so, please insert 'This work was supported by < insert the name of the funding agency in full $>$ ', followed by the grant number in square brackets '[grant number $\mathrm{xxxx}]$ '.

5. Supplemental data and underlying research materials: Do you wish to include the location of the underlying research materials (e.g. data, samples or models) for your article? If so, please insert this sentence before the reference section: 'The underlying research materials for this article can be accessed at $<$ full link $>/$ description of location [author to complete]'. If your article includes supplemental data, the link will also be provided in this paragraph. See $<$ http://journalauthors.tandf.co.uk/preparation/multimedia.asp $>$ for further explanation of supplemental data and underlying research materials.

6. The CrossRef database (www.crossref.org/) has been used to validate the references. Changes resulting from mismatches are tracked in red font.

\begin{tabular}{|l|l|}
\hline QUERY NO. & \\
\hline & QUERY DETAILS \\
\hline
\end{tabular}




\section{How to make corrections to your proofs using Adobe Acrobat/Reader}

Taylor \& Francis offers you a choice of options to help you make corrections to your proofs. Your PDF proof file has been enabled so that you can edit the proof directly using Adobe Acrobat/Reader. This is the simplest and best way for you to ensure that your corrections will be incorporated. If you wish to do this, please follow these instructions:

1. Save the file to your hard disk.

2. Check which version of Adobe Acrobat/Reader you have on your computer. You can do this by clicking on the "Help" tab, and then "About".

If Adobe Reader is not installed, you can get the latest version free from http://get.adobe.com/reader/.

3. If you have Adobe Acrobat/Reader 10 or a later version, click on the "Comment" link at the right-hand side to view the Comments pane.

4. You can then select any text and mark it up for deletion or replacement, or insert new text as needed. Please note that these will clearly be displayed in the Comments pane and secondary annotation is not needed to draw attention to your corrections. If you need to include new sections of text, it is also possible to add a comment to the proofs. To do this, use the Sticky Note tool in the task bar. Please also see our FAQs here: http://journalauthors.tandf.co.uk/production/index.asp.

5. Make sure that you save the file when you close the document before uploading it to CATS using the "Upload File" button on the online correction form. If you have more than one file, please zip them together and then upload the zip file.

If you prefer, you can make your corrections using the CATS online correction form.

\section{Troubleshooting}

Acrobat help: http://helpx.adobe.com/acrobat.html

Reader help: http://helpx.adobe.com/reader.html

Please note that full user guides for earlier versions of these programs are available from the Adobe Help pages by clicking on the link "Previous versions" under the "Help and tutorials" heading from the relevant link above. Commenting functionality is available from Adobe Reader 8.0 onwards and from Adobe Acrobat 7.0 onwards.

Firefox users: Firefox's inbuilt PDF Viewer is set to the default; please see the following for instructions on how to use this and download the PDF to your hard drive: http://support.mozilla.org/ en-US/kb/view-pdf-files-firefox-without-downloading-them\#w_using-a-pdf-reader-plugin 


\section{Planting Seeds So Something Bigger Might Emerge: The Paris Agreement and the Fight Against Climate Change}

FlyingLess: In a piece that you wrote and that was published in $N$ tud , you assert that the Paris climate agreement constitutes "a genuine trumph of international diplomacy," while at the same time arguing that it "risks being total fantasy." "Why do you say this?

Kevin Anderson: The triumph of Paris lies in the international diplomacy that brought together all the leaders of the world's countries. These leaders sang from the same hymn sheet for the first time and said that climate change is important, and, in doing so, pulled the rug from underneath the climate change skeptics. Ultimately, and despite their huge resource base, the skeptics have been unable to delegitimize the basic science of climate change. We have to look at this objectively and acknowledge that, in this respect at least, the Paris Agreement is a huge triumph and a real credit to how the French managed the whole process.

Another triumph is that we have gone further than just targets - I don't like the target framing anyway, as it suggests something that we merely aim for and that we may well miss; instead we now have obligations. These obligations are to stay well below a 2-degrees Celsius temperature increase over pre-industrial levels and to strive for 1.5 degrees. ${ }^{3}$ With these clear obligations we have something tangible

1. This is the edited transcript of an interview conducted for FlyingLess in early February 2016 by Joseph Nevins of Vassar College (Poughkeepsie, New York).

2. Kevin Anderson, "Talks in the City of Light Generate More Heat," Nature, Vol. 528, December 24-31, 2015: 437; http://www.nature.com/polopoly_fs/1.19074!/menu/ main/topColumns/topLeftColumn/pdf/528437a.pdf

3. A study released on April 21, 2016, the day before the signing of the Paris Agreement at the United Nations in New York, finds "substantial differences in impacts between 
against which we can and should hold governments, businesses, and wider civil society, accountable.

The remainder of the 32-page document has no meaningful substance in delivering on the temperature obligations - and it is in this sense that the agreement is a fantasy. Imagine an agreement on climate change that says nothing about de-carbonization, and doesn't even mention fossil fuels! The agreement doesn't take effect until 2020; by which time, the world will have emitted another 200 billion tons of carbon dioxide, leaving us little room in an already tight global carbon budget for 2-degrees Celsius and all but eliminating any chance to stay within 1.5 degrees of warming. Furthermore, the "Intended Nationally Determined Contributions" [INDCs] - the reductions in greenhouse gas emissions that each country has pledged to deliver - will lead us to an annual level of 55 billion tons of greenhouse gas emissions by 2030. The Paris document calls for these pledges to be tightened to deliver nearer 40 billion tons in 2030, but even this is far above what is compatible with a global average temperature rise of 2-degrees Celsius. ${ }^{4}$

So, when you do the maths, you see that the Agreement implies a 60 carbon budget far in excess of what is safe. ${ }^{5}$ Thus, the only way to reconcile the global emissions implied by the Agreement and the emission levels that are demanded by the science for "well below $2^{\circ} \mathrm{C}^{\text {" is by }}$ sucking an incredible amount of carbon out of the atmosphere, through the 'successful' roll out of highly speculative negative emissions technologies - technologies that do not yet, and may never, exist.

FlyingLess: If one were to ask high-level political leaders involved in the Paris negotiations what they think of your interpretation, what do you think they would say and why?

a $1.5^{\circ} \mathrm{C}$ and $2^{\circ} \mathrm{C}$ warming." Among the impacts, the $\frac{1}{2}$ degree increase in average global temperature, the authors assert, dangerously "marks the difference between events at the upper limit of present-day natural variability and a new climate regime, particularly in tropical regions." It also has "decisive" implications for the future of coral reefs. See Carl-Friedrich Schleussner et al., "Differential Climate Impacts for Policy-relevant Limits to Global Warming: The Case of $1.5{ }^{\circ} \mathrm{C}$ and $2^{\circ} \mathrm{C}$," Earth System Dynamics, Vol. 7, 2016: 327-351; http://www.earth-syst-dynam.net/ 7/327/2016/esd-7-327-2016.pdf

4. Research published after the Paris Agreement suggests that radical cuts to fossil fuel consumption must take place at a rate much faster than previously estimated. See Joeri Rogelj et al., "Differences Between Carbon Budgets Unravelled," Nature Climate Change Vol. 6, Issue 3, 2016: 245-252.

5. See "Adoption of the Paris Agreement," December 12, 2015; https://unfccc.int/ resource/docs/2015/cop21/eng/109.pdf 
Kevin Anderson: Away from a microphone, virtually all of those with a quantitative grasp of the issues would agree. The Paris Agreement explicitly avoids direct reference to its reliance on negative emissions technologies [NETs], yet the only way the sheer scale of the void between its temperature obligations and pathetic mitigation pathway can be reconciled is through heroic assumptions about some future reliance on NETs.

Obviously, it's a challenge to sell technologies that do not yet exist as the solution to a problem that is framed as needing to be resolved within a few decades, by 2050 at the latest. But there is a long history in the negotiations, and even in Working Group III of the IPCC [Intergovernmental Panel on Climate Change], of using politically palatable prescriptions as a way of pretending to resolve hugely challenging issues. Carbon offsetting, ${ }^{6}$ the clean development mechanism, joint implementation and emissions trading are all ruses to maintain the status quo whilst giving the impression of action. But empirical evidence gives the lie to these façades - emissions in 2016 will be over $60 \%$ higher than those in 1990, the year the first IPCC report was published. A quarter of a century of kicking the can down the road.

But there is a big caveat to what I've said here. Whilst the procrastination built into the Paris Agreement satisfies the inaction desired by fossil fuel companies, luddite politicians and timid academics, the 2degree Celsius obligation and the requirement for mitigation to be informed by the "best science" gives civil society a real opportunity to hold our governments to account. It is to support any such call for coherence and consistency in policies that the scientific community must speak out, with transparent assumptions, robust maths, and without concern for political sensibilities or the wrath of co-opted funders.

(17)ingLess: As you've made clear, you were in Paris. Why did you feel it was important for you to be there?

Kevin Anderson: I usually don't go to such events as I decided some time back to curtail my flying, but it was easy to get to Paris there are good train links across the Channel. I also have chosen not to attend the COPS [Conferences of the Parties, annual conferences held within the UN Framework Convention on Climate Change] because they are much more political than science events. But there are "side events" for scientists and I was aware that NETs wouldn't

6. For a strong critique of carbon offsets, see Kevin Anderson, "The Inconvenient Truth of Carbon Offsets," Nature, Vol. 484, Issue 7392, April 4, 2012: 7; http:/ / www.nature. $\mathrm{com} /$ news/the-inconvenient-truth-of-carbon-offsets-1.10373\#auth-1 
be talked about a lot, and that scientists needed to be there to raise concerns about their implicit inclusion in so much of the advice informing governments and negotiators. Colleagues and I also wanted to raise concerns about aviation and shipping emissions - a Cinderella issue at COPS.

In many of the side events where (integrated assessment) modelers were outlining their 'optimized' emission scenarios, NETs were simply taken as granted a - viable technology that could be applied at scale, accurately costed and used to avoid challenging mitigation rates today - but seldom, if ever, were NETs directly referred to. However, whilst this particular band of modelers appears to have almost no reservations about their heroic assumptions, there is considerable and increasing unease within the scientific community about the assumptions underlying NETs.

Five scientific colleagues and I were asked to contribute to a major press conference on the final day of the COP - to voice our concerns about the penultimate Paris text. The event was crammed with journalists hearing the same message from us all. The agreement, we said, lacked the teeth required to force governments to respond to climate change in a timely manner. We also argued that the INDC review process was too slow and would lock in levels of emissions far in excess of those required to hold below $2^{\circ} \mathrm{C}$, and most of us said that the reliance on NETs was misguided. Finally, we emphasized our grave concern that the document had dropped any reference to the importance of policies being informed by the best science.

We also raised our concerns about the omission of aviation and shipping from what proved to be the final text of the Convention. (As I recall, an early draft in Paris specifically mentioned aviation and shipping, ${ }^{7}$ but this was dropped from a subsequent version.)

Despite our efforts to make our concerns heard, the political leaders did not tighten the final text - other than the important inclusion of clear reference to being informed by the "best science."

In the frenetic organization of the press conference, there was considerable pressure put on those organizing it and some of those being asked to contribute to it not to rock the boat, to silence scientists from being scientists - to ensure that scientists did not do anything to undermine the possibility of an agreement.

Certainly it is, in part, the job of the diplomats to compromise and forge agreement, but to attempt to silence legitimate scientific debate is

7. See "Draft Paris Agreement," December 5, 2015; http://wwwwnature.com/news/ the-inconvenient-truth-of-carbon-offsets-1.10373\#auth-1. 
surely no more appropriate now than when the Catholic Church wielded its powers in the seventeenth century.

FlyingLess: Why is it important that the Agreement ultimately did not mention aviation and shipping? What makes these sectors distinct from, say, transport by trucks or trains, neither of which were mentioned in the agreement as well?

Kevin Anderson: Why aviation and shipping are important is that the $\mathrm{CO} 2$ emissions of the two sectors are roughly equivalent to the total emissions of Germany and the United Kingdom combined - and, worse still, they're anticipated to grow at far greater rates than the emissions of these two countries.

Moreover, ever since the Kyoto Protocol was adopted [in 1997], these sectors have been separated from the responsibilities of nationstates. What Kyoto did was to assign aviation to the International Civil Aviation Organization [ICAO] and shipping to the International Maritime Organization [IMO]. These specialized agencies of the United Nations are, in theory, responsible for the two sectors as if they were independent sovereign nations. For real nations, responsibility relates only to what are called territorial emissions. So, if there is a flight, for example, from London to Manchester, the emissions belong to the United Kingdom. But if there is a flight from London to New York City, the emissions do not belong to a particular country and thus no one - given the ICAO's inaction - is responsible for them.

FlyingLess: You yourself have not flown for 11 years. How did you come to that decision? Has it been difficult for you to adapt?

Kevin Anderson: My professional background is in the oil industry. I came to the university because I wanted to work on matters related to climate change as I thought it was an important issue. We so- me colleagues and I at the Tyndall Centre - started working on the UK's aviation emissions in 2002. And what we quickly realized was that the sector's emissions were substantial, rapidly growing and set to continue. Today, aviation emissions are about seven percent of the United Kingdom's total carbon emissions. So, for any chance of holding below 2-degrees Celsius, we concluded that there need to be far-reaching cuts in flying.

Now, if you work on a subject and your own research points clearly to your own behavior exemplifying the problem - well that presents a huge moral dilemma. What do you do? It seems to me that you have no choice but to work to put your personal behavior broadly in 
line with what your analysis demonstrates is necessary - at least if you think, for example, climate change is an important global issue.

It hasn't been too difficult for me to adapt. I don't have a no-fly policy, but rather a fly-less one. It's just that I've been able to avoid flying for many years because what I do is not sufficiently important to justify the emissions, which, in my view, is the case for almost all academics. If we're going to fly, it should be for truly extraordinary and important reasons. Otherwise, we shouldn't go or should take a slower form of travel and arrange for a longer visit; thinking through 210 pros and cons of flying engenders a very different attitude towards travel, time, emissions and moral responsibility. ${ }^{8}$

FlyingLess: You've referred to climate scientists and others who work on battling climate change, but also fly, as "hypocrites in the air." "Why are you so critical of academic flying?

Kevin Anderson: Flying is emblematic of our high-emissions lifestyles and the internationalization agenda of our universities - from conferences to students. Most of us who work in the area of climate change can see the dilemma but weakly justify our flying by asserting that what we do is more important than the emissions that we produce, a position trotted out by many business people, politicians and even some NGOs.

Alternatively, academics may deliberately avoid thinking about the issue - an easy first line of defense - self-inflicted ignorance implicitly placing the dilemma in the too-uncomfortable-to-handle box. But ultimately it is both arrogant and ineffective to point to the need for others to deliver major change if we are not willing to demonstrate how such changes can be viable within our own community. Leading by example may add not to the veracity of our research but from experience it certainly adds to the credibility.

Having said all this, we have to be careful not to pick on aviation. The issue is not flying in and of itself, but the fact that flying is such a carbon-fuel-intensive and emissions-spewing activity. There may come a day when we can substitute high-carbon kerosene for a zero or very low carbon alternative, at which point, from a purely climate change perspective, we can resume flying. So I'm not saying we have

8. See Joseph Nevins, "Academic Jet-setting in a Time of Climate Destabilization: Ecological Privilege and Professional Geographic Travel," The Professional Geographer, Vol. 66, Issue 2, 2014: 298-310.

9. Kevin Anderson, "Hypocrites in the Air: Should Climate Change Academics Lead by Example?" kevinanderson.info (blog), April 12, 2013; http://kevinanderson.info/ blog/hypocrites-in-the-air-should-climate-change-academics-lead-by-example/ 
to eliminate flying forever, but to hugely curtail it until we develop a truly zero carbon aviation sector. But we're very far from that point. Until that day arrives - if it ever does - we have no choice but to radically cut how much we fly.

FlyingLess: Given how important flying is for many universities and academics - especially in the relatively wealthy parts of the world - why can't we focus our cuts on other sectors so that those of us who do, and need to, fly can still do so?

Kevin Anderson: The first thing I'd say is, do the maths. With the Paris Agreement, we have committed to keep the temperature increase over pre-industrial levels to well below 2-degrees Celsius. The second is that we've also committed to deliver the necessary mitigation in line with principles of equity. ${ }^{10}$ This leaves the wealthy parts of the world those of us responsible for the lion's share of historical emissions ${ }^{11}$ needing to have zero emissions from our energy system by 2035, with poorer, "developing", nations following suite a few years later by 2050. If we take seriously the goal of 1.5 degrees, we have even less time. Alternatively, we can fudge the issue, keep on flying, celebrate efficiency - whilst conveniently ignoring growth - $^{-}$and finally rely on Dr Strangelove technologies to suck the CO2 out of the air many decades from now.

Sticking with the IPCC's carbon budgets, the enormity of the cuts we need to make across the board leaves no room for privileging a sector [aviation] at the expense of other sectors. All sectors are going to struggle to meet the reduction goals. There will be no spare capacity for aviation - that is unless, perhaps, we agree to close down energyintensive industries and give up completely driving and heating our homes. Maybe then we can have an occasional flight during the coming decade - but probably without luggage!

10. Increasing climate change may exacerbate global inequality. See Eli P. Fenichel et al, "Wealth Reallocation and Sustainability Under Climate Change," Nature Climate Change, Vol. 6, Issue 3, 2016: 237-244.

11. Regarding historical emissions, see Eric Holthaus and Chris Kirk, "A Filthy History," Slate, May, 28, 2014; http://www.slate.com/articles/technology/ future_tense/2014/05/carbon_dioxide_emissions_by_country_over_time_the_ worst_global_warming_polluters.html. See also S. Chakravarty et al. "Sharing Global $\mathrm{CO}_{2}$ Emission Reductions Among One Billion High Emitters," Proceedings of the National Academy of Sciences of the United States of America, Vol. 106, No. 29, 2009: 11884-11888; and David Satterthwaite, "The Implications of Population Growth and Urbanization for Climate Change," Environment and Urbanization, Vol. 21, Issue 2, 2009: 545-567. 
As for equity, given a set budget for global carbon emissions, every ton I use flying is a ton someone else can't use. In other words, flying, or any other high-carbon activity, imposes constraints on others - typically the poor. If I put a foot on a plane, I'm effectively telling a poor person elsewhere that they have to cut their already meagre emissions. ${ }^{12}$ The only way around this is to make spurious and trite arguments that the emissions of us wealthy "elite" are more important than those of others. This is the argument often made by academics and business people - typically senior and very high-emitting ones - an argument one hears much less from those with much lower emissions.

Furthermore, raising the welfare of those in poverty today requires improved access to energy, which, in the short- to medium-term, means their emissions will increase. To compensate for their rising emissions, we high emitters will have to deliver still more challenging rates of mitigation. Whilst for the poor increasing energy consumption goes hand in hand with improved welfare, beyond a certain point no further benefits are accrued - and us high-emitters are already far beyond this threshold.

So the wealthy of the world have to make very significant short- to medium-term sacrifices - at least in terms of energy consumption. There's no win-win solution in the near-term. The sooner we accept this, the sooner we can begin the social and technical innovations needed to provide a good and sustainable standard of living for all of us, not just the fortunate few.

FlyingLess: What do you say to people who argue that you put too heavy an emphasis on the individual and that we need to focus on structures and institutions?

Kevin Anderson: It is a mistake to see it in this way, to assume only a top-down approach will work. What I am not advocating are individualized, atomized actions, but "individual" actions that may catalyze wider meaningful mitigation, that help to change structures and systems.

Climate change is not only a very complicated problem, it is also a complex one - I'm using the word complex here in the way that a

12. According to Oxfam, the lowest 50 percent of the world's population in terms of income is responsible for about 10 percent of today's global carbon emissions; the richest 10 percent is responsible for almost half of the world's emissions. See Oxfam, "Extreme Carbon Inequality," Oxfam Media Briefing, December 2, 2015; http://www.theguardian.com/environment/2016/feb/25/fossil-fuel-use-mustfall-twice-fast-thought-contain-global-warming?CMP=share_btn_tw See also Chakravarty et al. 2009 and Satterthwaite 2009 (both cited in note 11). 
physicist may use it. Complex systems are not open to simple reductionist analyze In this case unpredictable emergent properties may arise from th 2 yriad of often tacit interactions between seven billion citizens. Most changes will not gain momentum, but occasionally some will - and even when new ideas fail, they may still catalyze further change elsewhere.

Within such an interpretation of society fumbling its way through the complexities of responding to climate change, individuals are what we first see manifesting potential systemic change. To succeed, examples of change need to gain momentum, be taken up by others, and finally be scaled up - perhaps through top-down nurturing and the development of specific policies.

I do not see the individual, or governments, international companies, etc., as wholly responsible for climate change or as the sole provider of a new model of a decarbonized society. It is a messy partnership without obvious boundaries - but within this we all have an opportunity to be potential agents of change. We cannot know from where or from who change will come -or, within reason, what may succeed and what may not. But if we choose simply to be content with the 340 status quo and not endeavor to drive change, then little new will be catalyzed and we'll continue to rely on very top-down polices masquerading as meaningful change.

Let me give an example. During the fight against apartheid in South Africa, Mary Manning, a 21-year-old cashier at Dunnes Stores, a supermarket in Dublin, Ireland, refused to ring up a grapefruit from South Africa at her register. Her boss suspended her as a result, but 10 of her fellow workers joined her in a strike, one that lasted more than two and a half years! The strike led to the government of Ireland banning South African goods in $1987 .^{13}$

Each individual is the interpreter of the millions of interactions that make us what we are - in that sense we all have the potential to offer a unique set of insights that may drive change. Small, ostensibly individual acts can attract support and translate into larger and potentially system-level change.

A twin concern in responding to climate change - or other huge challenges - is that we don't yet have systems-level paradigms or tools. And here universities are part of the problem. It is challenging because our structures appeal to us as individuals - worse still as

13. See Denise Oliver Velez, "Ordinary People Who Made a Difference: The Dunne Stores Strikers," Daily Kos, April 12, 2015; -Ordinary-people-who-made-a-difference-The-Dunnes-Stores-strikers 
consumers, and seldom ever as citizens. But just as the world can't be reduced to individuals or consumers, the world can't be reduced to academic disciplines. Reductionism has proved phenomenally successful - driving much of the industrial revolution - but it is simply inadequate for the scale and dynamism of the system challenges we now face; the whole is much more than the sum of the parts.

FlyingLess: On an institutional level, in terms of universities in the United Kingdom, do you see any initiatives, in relation to flying, for example, that provide grounds for hope?

Kevin Anderson: Yes, there are fledgling initiatives. In the Tyndall Centre for Climate Research, there have been some interesting developments - driven very significantly by Corinne Le Quére, the Tyndall director. She's not foresworn flying, but endeavors to carefully justify any flights she takes - and as such has significantly reduced how often she flies. Building on her individual action, Corinne has instigated an important study within the Tyndall Centre on low-carbon research ${ }^{14}$, and has also developed a "code of conduct" to promote low-carbon research within the Centre. 15 More recently, the Centre has produced 380 an app to help academics track their travel emissions on a yearly basis. ${ }^{16}$ The Travel Tracker requires researchers to explicitly justify their travel, while allowing them to compare their travel-related footprints with other researchers as well as with emissions targets.

Beyond the Tyndall Centre, there are discussions within research councils throughout the United Kingdom about carbon emissions related to travel and how to reduce them. And at the University of Leeds, I $\mathrm{m}$ aware of discussions regarding long-distance research and how this can be achieved without flying, or at least by reducing the frequency of flights

These are all seeds, early signs of something bigger that might emerge. Now if we could get the James Hansens and the 350.orgs of the world to follow suit, then that would certainly be a major catalyst for change - perhaps sufficient to begin to tip the status quo towards a new equilibrium.

14. See Corinne Le Quéré et al., "Towards a Culture of Low-carbon Research for the $21^{\text {st }}$ Century," Working Paper 161, Tyndall Centre for Climate Change Research, March 2015; http://tyndall.ac.uk/sites/default/files/twp161.pdf

15. See http://www.tyndall.ac.uk/travel-strategy

16. See Róisín Moriarty, "The Tyndall Travel Tracker: Cumulatively Changing our Travel Behavior One Flight at a Time," Future Earth blog, January 19, 2016; tyndall-travel-tracker-cumulatively-changing-our-travel-behavior-one-flight-time 